ECCOMAS

\section{Proceedia}

COMPDYN 2021

$8^{\text {th }}$ ECCOMAS Thematic Conference on Computational Methods in Structural Dynamics and Earthquake Engineering M. Papadrakakis, M. Fragiadakis (eds.) Streamed from Athens, Greece, 28 - 30 June 2021

\title{
APPLICATION AND ASSESSMENT OF A DYNAMIC SOIL-BRIDGE-TRAIN INTERACTION MODEL
}

\author{
Benjamin Hirzinger ${ }^{1,2}$ and Christoph Adam $^{2}$ \\ ${ }^{1}$ VCE Vienna Consulting Engineers, Department of Railway Engineering \\ Untere Viaduktgasse 2, 1030 Vienna, Austria \\ e-mail: hirzinger@vce.at \\ ${ }^{2}$ University of Innsbruck, Unit of Applied Mechanics \\ Technikerstr. 13, 6020 Innsbruck, Austria \\ e-mail: christoph.adam@uibk.ac.at
}

\begin{abstract}
In this contribution, the dynamic response of two railway bridges, represented by a viscoelastically supported Euler-Bernoulli model, subjected to high-speed trains is analyzed and discussed. Different types of high-speed trains are considered, which are modeled as moving mass-spring-damper (MSD) system. The structural response is determined by a dynamic substructuring approach, in which the equation of motion of the beam bridge model and the equations of motion of the MSD system, both written in state space, are coupled using a generalized corresponding assumption. The coupled set of equations of motion representing the dynamic soil-structure-vehicle interaction model are solved by time history analysis. The utilized approach captures all essential features of dynamic soil-structure-vehicle interaction and allows for a numerically efficient evaluation of the dynamic responses of the structure. Particular attention is paid to the influence of the MSD system on the beam bridge during approach and after departure. The structural response of the considered beam bridges is compared and discussed for the different types of high-speed trains and different subsoil conditions.
\end{abstract}

Keywords: Bridge Dynamics, Soil-Structure-Vehicle Interaction, Approach and Departure Phase, Dynamic Substructuring.

ISSN:2623-3347 (C) 2021 The Authors. Published by Eccomas Proceedia.

Peer-review under responsibility of the organizing committee of COMPDYN 2021.

doi: $10.7712 / 120121.8580 .18641$ 


\section{INTRODUCTION}

The increasing operational speed along train lines involves new challenges on the design of railway bridges and on the assessment of existing bridges. At certain train speeds, especially short-to-medium span railway bridges are excited to resonance, which leads to a significant structural acceleration response at the deck level [1]. Resonance effects can lead to destabilization of the ballast, to increased wearing of the rails which is associated with increased maintenance costs of the line, and in extreme cases even to the hazard of train derailment. These aspects demand a detailed dynamic analysis of the response behavior within the framework of a reliability assessment of bridge structures for trains with high-speed. In common computational models the subsoil of the bridge is assumed to be rigid and only a few studies deal with the influence of SSI on the dynamic response behavior of the bridge (e.g. [2, 3, 4, 5]). However, dynamic soil-structure interaction (SSI) effects may have a significant influence on the structural response of high-speed railway bridges and therefore should to be taken into account when performing a reliability analysis.

The most general modeling approach for the prediction of the structural response including SSI is provided by three-dimensional (3D) finite element (FE) models [4, 6, 7]. A 3D FE bridge model offers the possibility of taking the full coupling between the track and the soil into account, the geometry of the bridge can be modeled in detail, and in a time domain formulation nonlinear constitutive behavior can be implemented [3]. In a numerically more efficient but more elaborate approach, an FE model of the bridge is coupled with a boundary element (BE) model of the subsoil [3, 5, 8]. For instance, [5] investigated the influence of SSI on the structural responses of a single-span railway bridge subjected to moving trains at different speeds. In this study, a mass-spring-damper (MSD) train model is coupled with a 3D FE track and bridge model in combination with the BE soil model. The prediction of the structural bridge response using FE or BE-FE formulations involves a significant computational effort, and in the context of reliability assessment, where many limit state function evaluations are required, it is not feasible to use such complex and computationally expensive models. For this reason, the authors of this paper have recently developed a numerically efficient dynamic soil-structure and bridge-train interaction model [9] that allows for a large number of computations in the context of a reliability analysis.

In this contribution, this model is utilized to determine the structural response of beam bridges subjected to moving high-speed trains. The trains are modeled as a planar MSD system, and the bridges as an Euler-Bernoulli beam resting at both ends on spring-damper elements that capture the effect of the subsoil. A dynamic substructuring approach is used to determine the system response, in which the equation of motion of the beam bridge model and the equations of motion of the MSD system are written separately in state space and then coupled via a generalized corresponding assumption. Particular emphasis is paid to the influence of the MSD system on the bridge response during approach and after departure of the bridge. In two application examples, the structural response of two existing bridge structures subjected to three different German high-speed InterCity Express (ICE) trains is assessed.

\section{DYNAMIC SOIL-BRIDGE-TRAIN INTERACTION MODEL}

\subsection{Dynamic substructuring approach}

The response of the coupled bridge-MSD system is found by a dynamic substructuring technique [9]. In this approach, the equations of motion of the two subsystems (i.e., the bridge and the MSD system) are derived separately and then coupled utilizing a coupling condition at the interfaces of the subsystems. The beam bridge is subjected to a planar viscoelastic 
MSD system representing the moving train at constant speed $v$ (see Figure 1). To account for soil-structure interaction effects, the bridge is modeled as an Euler-Bernoulli beam with spring-dashpot elements at both ends, which is thus non-classically damped. In addition, the rotational springs consider the bending stiffness of the rails and the lumped masses account for the mass of the foundation (see Figure 1).

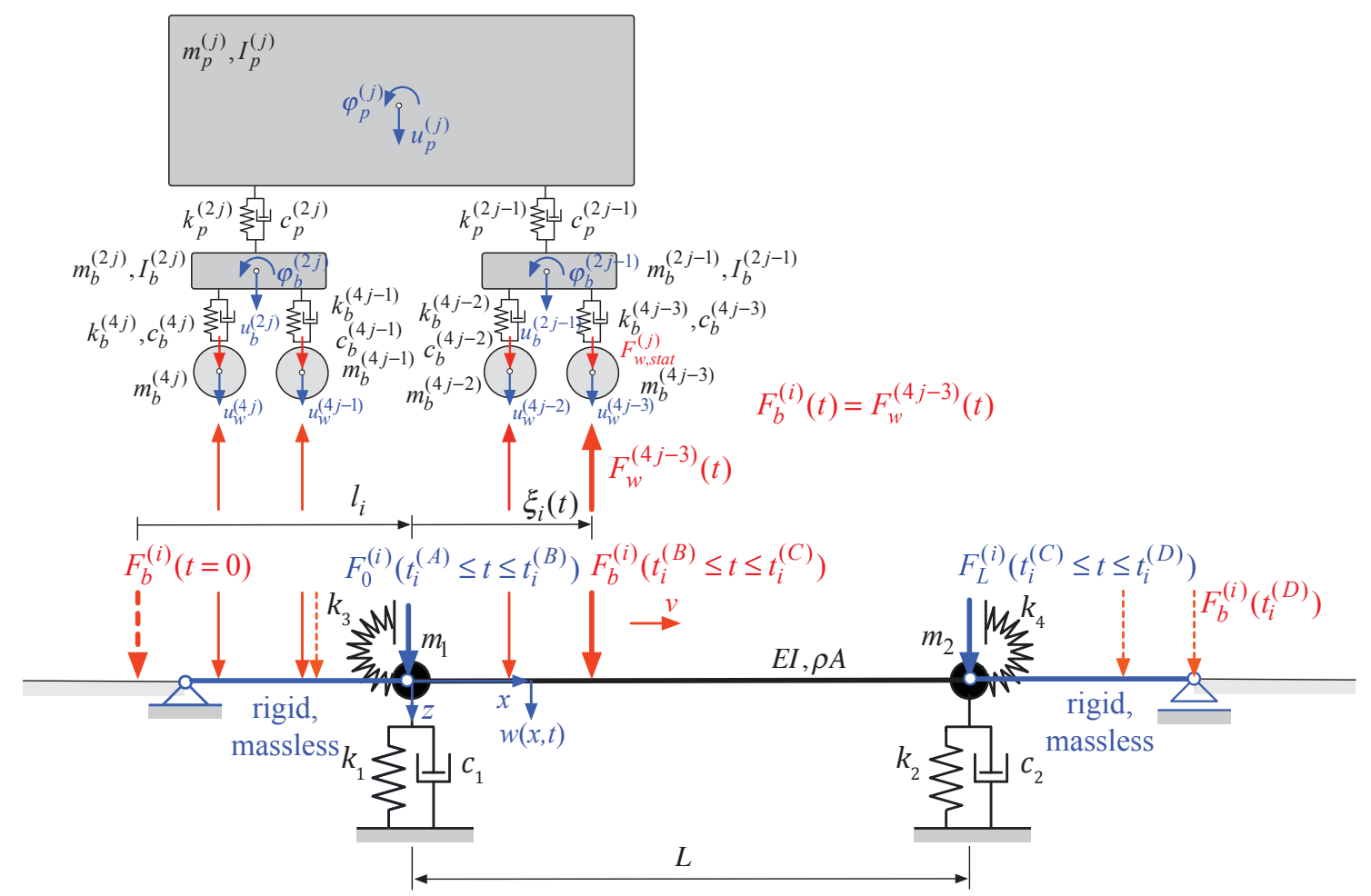

Figure 1: Viscoelastically supported Euler-Bernoulli beam model and planar MSD model, modified from [9]

The procedure described in [9] is based on a complex modal series representation of the beam bridge displacement $w(x, t)$ and the acceleration $\ddot{w}(x, t)$,

$$
w(x, t) \approx 2 \mathcal{R}\left\{\sum_{r=1}^{N_{\Phi}} \Phi_{r}(x) y_{r}(t)\right\}, \ddot{w}(x, t) \approx 2 \mathcal{R}\left\{\sum_{r=1}^{N_{\Phi}} \Phi_{r}(x) s_{r} \dot{y}_{r}(t)\right\}
$$

with $\Phi_{r}(x)$ denoting the $r$-th complex eigenfunction of the non-classically damped beam and $s_{r}$ is the corresponding complex natural frequency. The modal equations of motion in state space for the first $N_{\Phi}$ modes of the Euler-Bernoulli beam read [9]

$$
\mathbf{A}_{b} \dot{\mathbf{y}}+\mathbf{B}_{b} \mathbf{y}=\mathbf{f}_{b}
$$

where $\mathbf{y}$ is the vector of the complex modal coordinates $y_{r}, r=1, \ldots, N_{\Phi}$, and their conjugate complex counterparts $\bar{y}_{r}$, matrix $\mathbf{A}_{b}$ contains the coefficients of the decoupled first order differential equations related with $\dot{\mathbf{y}}$, matrix $\mathbf{B}_{b}$ the coefficients related with $\mathbf{y}$, and $\mathbf{f}_{b}$ denotes the vector of the modal interaction forces $f_{r}$ and $\bar{f}_{r}, r=1, \ldots, N_{\Phi}$, between the bridge and the train model,

$$
\begin{aligned}
& \mathbf{y}=\left[y_{1}, \ldots, y_{r}, \ldots, y_{N_{\Phi}}, \bar{y}_{1}, \ldots, \bar{y}_{r}, \ldots, \bar{y}_{N_{\Phi}}\right]^{T}, \\
& \mathbf{A}_{b}=\operatorname{diag}\left[a_{1}, \ldots, a_{r}, \ldots, a_{N_{\Phi}}, \bar{a}_{1}, \ldots, \bar{a}_{r}, \ldots, \bar{a}_{N_{\Phi}}\right], \\
& \mathbf{B}_{b}=\operatorname{diag}\left[b_{1}, \ldots, b_{r}, \ldots, b_{N_{\Phi}}, \bar{b}_{1}, \ldots, \bar{b}_{r}, \ldots, \bar{b}_{N_{\Phi}}\right], \\
& \mathbf{f}_{b}=\left[f_{1}, \ldots, f_{r}, \ldots, f_{N_{\Phi}}, \bar{f}_{1}, \ldots, \bar{f}_{r}, \ldots, \bar{f}_{N_{\Phi}}\right]^{T}
\end{aligned}
$$


The MSD train system is composed of rigid bodies with mass representing the passenger stage, two bogies, and four wheel pairs connected with spring-dashpot elements, as shown in Figure $1[10,11]$. The equations of motion of this MSD system with 10 degrees of freedom (DOFs) in state space representation are given as [11, 12],

$$
\mathbf{A}_{c} \dot{\mathbf{d}}_{c}(t)+\mathbf{B}_{c} \mathbf{d}_{c}(t)=\mathbf{f}_{c}(t)
$$

with the matrices $\mathbf{A}_{c}, \mathbf{B}_{c}$, and vector $\mathbf{f}_{c}$

$$
\mathbf{A}_{c}=\left[\begin{array}{cc}
\mathbf{C}_{c} & \mathbf{M}_{c} \\
\mathbf{I}_{c} & \mathbf{0}
\end{array}\right], \quad \mathbf{B}_{c}=\left[\begin{array}{cc}
\mathbf{K}_{c} & \mathbf{0} \\
\mathbf{0} & -\mathbf{I}_{c}
\end{array}\right], \quad \mathbf{f}_{c}=\left[\begin{array}{c}
\mathbf{F}_{c} \\
\mathbf{0}
\end{array}\right]
$$

composed of the mass matrix $\mathbf{M}_{c}$, the damping matrix $\mathbf{C}_{c}$, the stiffness matrix $\mathbf{K}_{c}$, the vector $\mathbf{F}_{c}$ comprising the axle forces, and the identity matrix $\mathbf{I}_{c}$. The vector $\mathbf{d}_{c}=\left\{\mathbf{u}_{c}^{(1)}, \ldots, \mathbf{u}_{c}^{(j)}, \ldots, \mathbf{u}_{c}^{\left(N_{c}\right)}\right.$, $\left.\dot{\mathbf{u}}_{c}^{(1)}, \ldots, \dot{\mathbf{u}}_{c}^{(j)}, \ldots, \dot{\mathbf{u}}_{c}^{\left(N_{c}\right)}\right\}^{T}$ contains all DOFs of the MSD system and their first derivative in time of the DOFs.

The equation of motions of beam and MSD system are coupled with the so-called generalized corresponding assumption [9, 13], where it is assumed that the displacement in the vertical direction of the beam and the MSD system at the contact point are equal. Consequently, lift-off of the wheels is not possible, see Figure 2. The generalized corresponding assumption yields the following expression for the vertical displacement $u_{w}^{(i)}$ of the $i$-th wheel, which is at time $t$ at position $\xi_{i}(t)$, together with Eq. (1) [9],

$$
u_{w}^{(i)}\left(\xi_{i}\right)=w\left(\xi_{i}, t\right) \approx \sum_{r=1}^{N_{\Phi}} \Phi_{r}\left(\xi_{i}\right) y_{r}(t)+\sum_{r=1}^{N_{\Phi}} \bar{\Phi}_{r}\left(\xi_{i}\right) \bar{y}_{r}(t)
$$

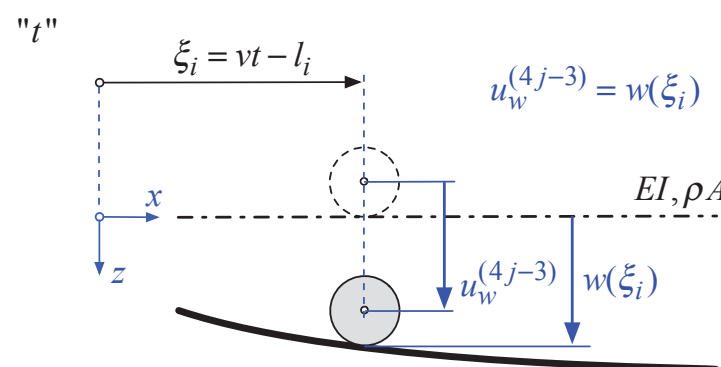

Figure 2: Generalized corresponding assumption for beam and wheel contact at position $\xi_{i}(t)$ [9]

Finally, the resulting coupled set of equations of motion in state space reads as $[9,13]$

$$
\mathbf{A}^{*}(t) \dot{\mathbf{x}}^{*}(t)+\mathbf{B}^{*}(t) \mathbf{x}^{*}(t)=\mathbf{f}^{*}(t)
$$

with the time-dependent system matrices

$$
\begin{aligned}
& \mathbf{A}^{*}(t)=\boldsymbol{\Gamma}_{1}^{T}(t)\left[\mathbf{A} \boldsymbol{\Gamma}_{1}(t)+\mathbf{A} \dot{\boldsymbol{\Gamma}}_{2}(t)+\mathbf{A} \boldsymbol{\Gamma}_{2}(t) \mathbf{S}+\mathbf{B} \boldsymbol{\Gamma}_{2}(t)\right], \\
& \mathbf{B}^{*}(t)=\boldsymbol{\Gamma}_{1}^{T}(t)\left[\mathbf{A} \dot{\boldsymbol{\Gamma}}_{1}(t)+\mathbf{B} \boldsymbol{\Gamma}_{1}(t)\right]
\end{aligned}
$$

and

$$
\mathbf{f}^{*}(t)=\boldsymbol{\Gamma}_{1}^{T}(t)[\mathbf{f}(t)-\mathbf{A} \dot{\Upsilon}(t)-\mathbf{B} \Upsilon(t)]
$$


The time-dependent transformation matrices $\Gamma_{1}(t), \Gamma_{2}(t)$ include terms that consider the interaction between the subsystems. This system of equations is solved for the vector $\mathbf{x}^{*}$ utilizing the 4-th order numerical Runge-Kutta time-step integration scheme of the explicit form of Eq. (7), i.e. $\dot{\mathbf{x}}^{*}(t)=\mathbf{A}^{*}(t)^{-1}\left(\mathbf{f}^{*}(t)-\mathbf{B}^{*}(t) \mathbf{x}^{*}(t)\right)$. A detailed derivation of the equations of motions of the beam bridge model and the MSD system can be found in $[9,13]$.

\subsection{Modeling of the approach and departure phase of the train}

When the train approaches the bridge, the bridge is lowered slightly due to the flexibility of the subsoil. This lowering must be taken into account in the mechanical model to avoid a physically unreasonable acceleration jump in the calculation. The same applies accordingly after the train has left the bridge. As described in [14], in the mechanical model the lowering of the bridge in the approach and departure phases is achieved by two fictitious massless rigid beams placed before and after the bridge, respectively, as shown in Figure 1. The effect of $N_{w}$ axle loads of the MSD system in the approach phase on the first massless beam and in further consequence on the bridge model can be simply described by a force on the left support $F_{0}(t)$ (at $x=0$ ) that increases linearly in this phase [14],

$$
F_{0}(t)=\sum_{i=1}^{N_{w}} F_{b}^{(i)}(t)\left(1+\frac{v t-l_{i}}{L_{a}}\right) \delta(x) \Pi\left(t, t_{i}^{(A)}, t_{i}^{(B)}\right)
$$

where the Dirac delta function $\delta(x)$ indicates the position of $F_{0}(t)$ at $x=0$, i.e. at the left beam support. The $i$-th force $F_{b}^{(i)}$ is activated at time $t_{i}^{(A)}=\left(l_{i}-L_{\mathrm{a}}\right) / v$ by the Heaviside function $H\left(t-t_{i}^{(A)}\right)$ when it enters the fictitious rigid beam, and at time $t_{i}^{(B)}=l_{i} / v$ deactivated by the Heaviside function $H\left(t-t_{i}^{(B)}\right)$ when $F_{b}^{(i)}$ runs onto the flexible support, i.e., $\Pi\left(t, t_{i}^{(A)}, t_{i}^{(B)}\right)=$ $H\left(t-t_{i}^{(A)}\right)-H\left(t-t_{i}^{(B)}\right)$. Accordingly, a single force $F_{L}(t)$ on the right support (at $x=L$ ) captures the movement of the train away from the bridge [9],

$$
F_{L}(t)=\sum_{i=1}^{N_{w}} F_{b}^{(i)}(t)\left(1-\frac{v t-l_{i}-L}{L_{\mathrm{d}}}\right) \delta(x-L) \Pi\left(t, t_{i}^{(C)}, t_{i}^{(D)}\right)
$$

At time $t_{i}^{(C)}=\left(l_{i}+L\right) / v$ the $i$-th force of the MSD system leaves the beam bridge, and at time $t_{i}^{(D)}=\left(l_{i}+L+L_{\mathrm{d}}\right) / v$ it leaves the fictitious rigid beam of length $L_{\mathrm{d}}$, consequently, $\Pi\left(t, t_{i}^{(C)}, t_{i}^{(D)}\right)=H\left(t-t_{i}^{(C)}\right)-H\left(t-t_{i}^{(D)}\right)$.

The $r$-th modal form of these forces read as [9]

$$
\begin{aligned}
& f_{0}^{(r)}(t)=\int_{L} \sum_{i=1}^{N_{w}} F_{b}^{(i)}\left(1+\frac{v t-l_{i}}{L_{\mathrm{a}}}\right) \delta(x) \Pi\left(t, t_{i}^{(A)}, t_{i}^{(B)}\right) \Phi_{r}(x) d x= \\
& \sum_{i=1}^{N_{w}} F_{b}^{(i)}\left(1+\frac{v t-l_{i}}{L_{\mathrm{a}}}\right) \Pi\left(t, t_{i}^{(A)}, t_{i}^{(B)}\right) \Phi_{r}(0) \\
& f_{L}^{(r)}(t)=\int_{L} \sum_{i=1}^{N_{w}} F_{b}^{(i)}\left(1-\frac{v t-l_{i}-L}{L_{\mathrm{d}}}\right) \delta(x-L) \Pi\left(t, t_{i}^{(E)}, t_{i}^{(F)}\right) \Phi_{r}(x) d x= \\
& \sum_{i=1}^{N_{w}} F_{b}^{(i)}\left(1-\frac{v t-l_{i}-L}{L_{\mathrm{d}}}\right) \Pi\left(t, t_{i}^{(E)}, t_{i}^{(F)}\right) \Phi_{r}(L)
\end{aligned}
$$


Consequently, the $r$-th modal load in Eq. (3) is given as $f_{r}=f_{0}^{(r)}+f_{b}^{(r)}+f_{L}^{(r)}$, where $f_{b}^{(r)}(t)=$ $\int_{L} \sum_{i=1}^{N_{w}} F_{b}^{(i)}(t) \delta\left(x-\xi_{i}\right) \Pi\left(t, t_{i}^{(B)}, t_{i}^{(C)}\right) \Phi_{r}(x) d x=\sum_{i=1}^{N_{w}} F_{b}^{(i)}(t) \Pi\left(t, t_{i}^{(B)}, t_{i}^{(C)}\right) \Phi_{r}\left(\xi_{i}\right)$ accounts for the modal form of the series of $N_{w}$ moving single forces crossing the beam bridge. During the approach and departure phase of the MSD system the dynamic interaction between the beam and the MSD system is explicitly considered in the transformation matrices $\Gamma_{1}(t), \Gamma_{2}(t)$, see $[9,13]$.

\section{Application}

This dynamic substructuring approach is used to efficiently evaluate the acceleration response of two example bridges subjected to the German InterCity Express trains ICE 2, ICE 3, and ICE 4. In the considered configuration, the ICE 2 train with a maximum train speed of $v_{\max }=77.8 \mathrm{~m} / \mathrm{s}$ $(280 \mathrm{~km} / \mathrm{h})$ and a total length of $L_{\text {train }}=205.4 \mathrm{~m}$ is composed of one power car followed by seven passenger cars. The UIC axle classification [15] of this train with in total 32 axles thus reads $\mathrm{Bo}^{\prime} \mathrm{Bo}^{\prime}+2^{\prime} 2^{\prime}+2^{\prime} 2^{\prime}+2^{\prime} 2^{\prime}+2^{\prime} 2^{\prime}+2^{\prime} 2^{\prime}+2^{\prime} 2^{\prime}+2^{\prime} 2^{\prime}$, with $\mathrm{Bo}^{\prime}$ representing one pair of axles of the power car and $2^{\prime}$ representing one pair of axles of the passenger car. The considered ICE 3 train contains four power cars and four passenger cars with an UIC axle classification of $\mathrm{Bo}^{\prime} \mathrm{Bo}^{\prime}+2^{\prime} 2^{\prime}+\mathrm{Bo}^{\prime} \mathrm{Bo}^{\prime}+2^{\prime} 2^{\prime}+2^{\prime} 2^{\prime}+\mathrm{Bo}^{\prime} \mathrm{Bo}^{\prime}+2^{\prime} 2^{\prime}+\mathrm{Bo}^{\prime} \mathrm{Bo}^{\prime}$. The length of this train with 32 axles and a maximum speed of $v_{\max }=91.4 \mathrm{~m} / \mathrm{s}(330 \mathrm{~km} / \mathrm{h})$ is $L_{\text {train }}=200.8 \mathrm{~m}$. The considered ICE 4 train with a maximum speed of $v_{\max }=69.4 \mathrm{~m} / \mathrm{s}(250 \mathrm{~km} / \mathrm{h})$ has 3 power cars and 4 passenger cars, which add up to 28 axles and a total length of $L_{\text {train }}=202 \mathrm{~m}$. The corresponding UIC axle classification is $2^{\prime} 2^{\prime}+\mathrm{Bo}^{\prime} \mathrm{Bo}^{\prime}+2^{\prime} 2^{\prime}+\mathrm{Bo}^{\prime} \mathrm{Bo}^{\prime}+\mathrm{Bo}^{\prime} \mathrm{Bo}^{\prime}+2^{\prime} 2^{\prime}+2^{\prime} 2^{\prime}$. The parameters of the MSD model of the ICE 2 and ICE 3 can be found in [16, 17], and of the ICE 4 train in [18].

In general, the maximum acceleration of the bridge deck is decisive for the assessment of the reliability of the railway bridge exposed to high-speed trains [19]. Therefore, the acceleration response of the two beam bridges subjected to the MSD system representing the considered trains is computed for five different subsoil conditions. In this study, the time history of the beam bridge response at closely spaced beam locations $x$ is analyzed for a given speed $v$ of the train models in the observation period $T=\left(l_{1}+L_{\text {train }}+L_{\mathrm{a}}+L+L_{\mathrm{d}}\right) / v$, and subsequently the absolute value of the peak response is recorded, i.e. the peak acceleration $a(v)=\max \{|\ddot{w}(x, t, v)|: 0 \leq x \leq L, 0 \leq t \leq T\}$. The modal expansions are approximated by seven modes, i.e. $N_{\Phi}=7$. Structural modal damping of $\widetilde{\zeta}_{r}=0.25 \%\left(r=1, \ldots, N_{\Phi}\right)$ is taken into account and the surface of the beam is assumed to be perfectly smooth.

The properties of the soil under the bridge foundation are varied, representing a range from moderately soft to stiff soils. Five homogeneous soils with different stiffness are considered, whose soil parameters (constrained modulus $E_{s}$, Poisson's ratio $\nu$, mass density $\rho$ ) are summarized in Table $1[13,20]$. Soil 1 with the lowest stiffness corresponds to a medium stiff soil and soil 5 to a stiff soil (rock). Since the required contact area $A_{0}$ of the foundations depends on the soil stiffness (i.e. the stiffer the soil the smaller the required area), the product of the base area of the foundation $A_{0}$ and the root of the constrained modulus of the soil $E_{s}$ is kept constant when determining $k$ and $c$, i.e., $A_{0} \sqrt{E_{s}}=2.289 \cdot 10^{4} \sqrt{\mathrm{Nm}}$ [14]. It is assumed that the foundation has the same mass for all soils considered: $m=1.5 \cdot 10^{5} \mathrm{~kg}$. 


\begin{tabular}{cccccc}
\hline & $\begin{array}{c}E_{s} \\
{\left[\mathrm{MN} / \mathrm{m}^{2}\right]}\end{array}$ & $\begin{array}{c}\rho \\
{[-]}\end{array}$ & $\begin{array}{c}\rho \\
{\left[\mathrm{kg} / \mathrm{m}^{3}\right]}\end{array}$ & $\begin{array}{c}k \\
{[\mathrm{~N} / \mathrm{m}]}\end{array}$ & $\begin{array}{c}c \\
{[\mathrm{~kg} / \mathrm{s}]}\end{array}$ \\
\hline 1 & 200 & 0,30 & 2263 & $5,895 \cdot 10^{8}$ & $1,089 \cdot 10^{6}$ \\
2 & 250 & 0,28 & 2300 & $7,662 \cdot 10^{8}$ & $1,098 \cdot 10^{6}$ \\
3 & 300 & 0,26 & 2333 & $9,495 \cdot 10^{8}$ & $1,106 \cdot 10^{6}$ \\
4 & 400 & 0,25 & 2367 & $1,284 \cdot 10^{9}$ & $1,114 \cdot 10^{6}$ \\
5 & 500 & 0,25 & 2400 & $1,605 \cdot 10^{9}$ & $1,121 \cdot 10^{6}$ \\
\hline
\end{tabular}

Table 1: Soil parameters and corresponding parameters of the spring-dashpot elements [13]

\subsection{Example bridge 1}

Example bridge 1 models an existing single-span ballasted steel railway bridge located in Austria with a span length of $L=16.8 \mathrm{~m}$. Its bending stiffness is $E I=3.262 \cdot 10^{10} \mathrm{Nm}^{2}$ and its mass per unit length $\rho A=1.220 \cdot 10^{4} \mathrm{~kg} / \mathrm{m}$. Table 2 presents the first four natural frequencies $f_{r}\left(=\mathcal{I}\left(s_{r}\right) / 2 \pi=\Omega_{r} / 2 \pi\right), r=1, \ldots, 4$, and equivalent damping coefficients $\zeta_{r}+\widetilde{\zeta}_{r}$ for the beam model on viscoelastic supports representing various subsoil conditions, and for the simply supported beam bridge model (i.e., in this case the subsoil is rigid). In this context, it should be noted that higher modes, associated with higher frequencies, are less critical for bridge failure [13].

Table 2: First four natural frequencies and damping coefficients of bridge model 1 resting on soils 1 to 5 and on rigid soil

\begin{tabular}{ccccccc}
\hline & soil no. 1 & soil no. 2 & soil no. 3 & soil no. 4 & soil no. 5 & simply supported beam \\
\hline$f_{1}[\mathrm{~Hz}]$ & 6.59 & 7.12 & 7.49 & 7.94 & 8.19 & 9.10 \\
$f_{2}[\mathrm{~Hz}]$ & 8.96 & 10.19 & 11.34 & 13.16 & 14.68 & 36.39 \\
$f_{3}[\mathrm{~Hz}]$ & 12.96 & 13.68 & 14.45 & 15.87 & 17.19 & 81.90 \\
$f_{4}[\mathrm{~Hz}]$ & 38.80 & 38.85 & 38.89 & 38.99 & 39.08 & 145.60 \\
$\zeta_{1}+\widetilde{\zeta}_{1}[\%]$ & 2.71 & 1.96 & 1.46 & 0.94 & 0.69 & 0.25 \\
$\zeta_{2}+\widetilde{\zeta}_{2}[\%]$ & 5.41 & 4.79 & 4.35 & 3.77 & 3.39 & 0.25 \\
$\zeta_{3}+\widetilde{\zeta}_{3}[\%]$ & 2.94 & 3.17 & 3.20 & 3.18 & 3.08 & 0.25 \\
$\zeta_{4}+\widetilde{\zeta}_{4}[\%]$ & 0.42 & 0.43 & 0.44 & 0.45 & 0.46 & 0.25 \\
\hline
\end{tabular}

Figure 3 shows the maximum acceleration response $a(v)$ of example bridge 1 subjected (a) to the ICE 2 train and (b) to the ICE 3 train as a function of the train speed $v$. The local response peaks of these so-called response spectra are referred to as resonance peaks, and the associated train speeds are known as critical speeds or resonance speeds. At such a critical train speed, defined as $v_{j}^{(r)}=d f_{r} / j, j=1,2,3, \ldots$, the $r$-th natural bridge frequency is excited to a state of resonance due to the repetitive axle loads with constant distance $d$ [21].

When the beam is rigidly supported, the ICE 2 train induces a maximum bridge deck acceleration $a=6.6 \mathrm{~m} / \mathrm{s}^{2}$ at speed $v=79.5 \mathrm{~m} / \mathrm{s}$ (which is close to the resonance speed $v_{3}^{(1)}=80.1 \mathrm{~m} / \mathrm{s}$, based on the wagon length of the ICE 2 train $d=26.4 \mathrm{~m}$ ). For the beam resting on soil 5 , the maximum acceleration $a=3.6 \mathrm{~m} / \mathrm{s}^{2}$ occurs at the train speed $v=71 \mathrm{~m} / \mathrm{s}$, which is close to the resonance speed $v_{3}^{(1)}=72.1 \mathrm{~m} / \mathrm{s}$. Soil 4 and soil 3 lead to the acceleration maxima $a=2.9 \mathrm{~m} / \mathrm{s}^{2}$ and $a=1.9 \mathrm{~m} / \mathrm{s}^{2}$ at the train speeds $v=68.8 \mathrm{~m} / \mathrm{s}, v=66.7 \mathrm{~m} / \mathrm{s}$, respectively. Due to the considerable geometric damping at soil 1 and soil 2, no pronounced resonance peak is visible in these cases. These results show that SSI reduces the peak accelerations at resonance compared to the rigidly supported beam bridge model. Simultaneously, the corresponding critical train speeds 
also decrease, which could be of concern because these speeds are below the maximum train speed (cf. Figure 3(a)).

The overall response behavior of this example bridge is very similar when subjected to the ICE 3 train, see Figure 3. In the rigidly supported beam bridge model, the global acceleration maximum at $v=74.6 \mathrm{~m} / \mathrm{s}$ is $a=10.3 \mathrm{~m} / \mathrm{s}^{2}$, which is close to the resonance speed $v_{3}^{(1)}=$ $75.2 \mathrm{~m} / \mathrm{s}$, based on the ICE 3 wagon length $d=24.8 \mathrm{~m}$. The global resonance peak of the bridge resting on soil 5 is $a=5.7 \mathrm{~m} / \mathrm{s}^{2}$ at $v=66.7 \mathrm{~m} / \mathrm{s}$ (close to resonance speed $v_{3}^{(1)}=67.6 \mathrm{~m} / \mathrm{s}$ ). The structure in combination with soil 4 yields the maximum acceleration $a=4.1 \mathrm{~m} / \mathrm{s}^{2}$ at $v=64.7 \mathrm{~m} / \mathrm{s}$, and in combination with soil $3 a=2.6 \mathrm{~m} / \mathrm{s}^{2}$ at $v=60.4 \mathrm{~m} / \mathrm{s}$. As in the case of the ICE 2 train, no distinct acceleration peaks can be observed for the structure resting on soil 1 and soil 2.
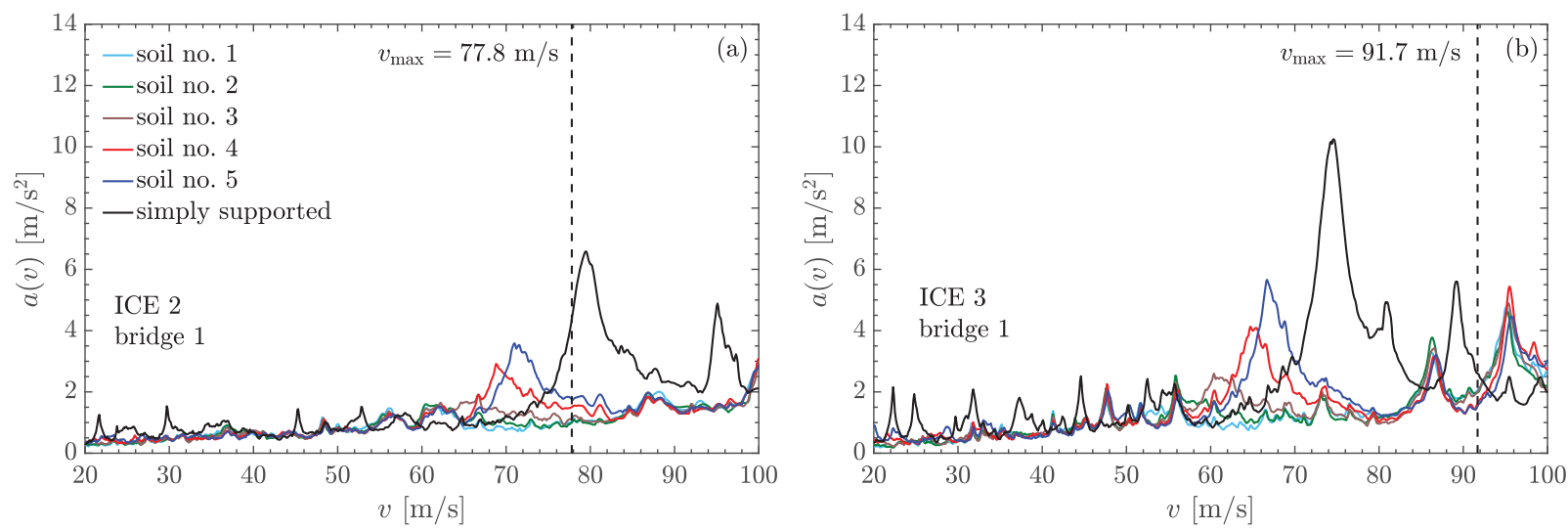

Figure 3: Maximum bridge acceleration of example bridge 1 subjected (a) to the ICE 2 train and (b) to the ICE 3 train as a function of the train speed for different soil conditions.

Figure 4 presents the maximum acceleration response of example bridge 1 subjected to the MSD system of the ICE 4 train. As before, the rigidly supported beam bridge model exhibits the largest bridge deck acceleration $a=12.6 \mathrm{~m} / \mathrm{s}^{2}$ at $v=86.4 \mathrm{~m} / \mathrm{s}$ (close to the resonance speed $v_{3}^{(1)}=87.7 \mathrm{~m} / \mathrm{s}$; wagon length $\left.d=28.9 \mathrm{~m}\right)$. Likewise, the maximum bridge acceleration and the associated resonant speed decrease with decreasing base stiffness (soil 5: $a=7.9 \mathrm{~m} / \mathrm{s}^{2}$ at $v=77.7 \mathrm{~m} / \mathrm{s}$; soil 4: $a=6.7 \mathrm{~m} / \mathrm{s}^{2}$ at $v=74.5 \mathrm{~m} / \mathrm{s} ;$ soil 3: $a=4.9 \mathrm{~m} / \mathrm{s}^{2}$ at $v=70.7 \mathrm{~m} / \mathrm{s} ;$ soils 1 and 2: no pronounced response peaks).

Comparison of Figures 3 and 4 reveals that at bridge 1 on rigid soil the ICE 3 train leads to the dominant resonance peak at the lowest speed, while the ICE 2 train induces the lowest bridge accelerations. On the other hand, the ICE 4 train excites the bridge to the largest accelerations, however, at the largest resonance speed compared to the other train models. 


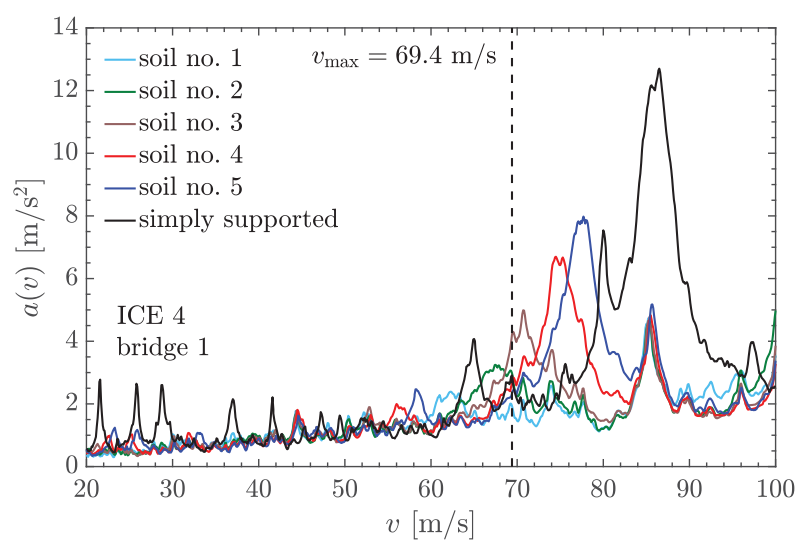

Figure 4: Maximum bridge acceleration of example bridge 1 subjected to the ICE 4 as a function of the train speed for different soil conditions.

\subsection{Example bridge 2}

With $L=21 \mathrm{~m}$, the span length of example bridge 2, which is also the model of an existing single-span ballasted steel railway bridge, is larger than that of bridge 1 . The flexural stiffness is $E I=2.6 \cdot 10^{10} \mathrm{Nm}^{2}$ and the mass per unit length $\rho A=7083 \cdot 10^{4} \mathrm{~kg} / \mathrm{m}$. The first four natural frequencies of example bridge $2 f_{r}, r=1, \ldots, 4$, and corresponding equivalent damping coefficients $\zeta_{r}+\widetilde{\zeta}_{r}$ depending on the subsoil conditions are compiled in Table 3.

Table 3: First four natural frequencies and damping coefficients of bridge model 2 resting on soils 1 to 5 and on rigid soil

\begin{tabular}{ccccccc}
\hline & soil no. 1 & soil no. 2 & soil no. 3 & soil no. 4 & soil no. 5 & simply supported beam \\
\hline$f_{1}[\mathrm{~Hz}]$ & 5.96 & 6.19 & 6.33 & 6.47 & 6.55 & 6.80 \\
$f_{2}[\mathrm{~Hz}]$ & 9.18 & 10.45 & 11.61 & 13.44 & 14.96 & 27.20 \\
$f_{3}[\mathrm{~Hz}]$ & 10.88 & 11.95 & 13.01 & 14.79 & 16.35 & 61.20 \\
$f_{4}[\mathrm{~Hz}]$ & 28.62 & 28.67 & 28.73 & 28.85 & 28.99 & 108.80 \\
$\zeta_{1}+\widetilde{\zeta}_{1}[\%]$ & 1.40 & 0.91 & 0.67 & 0.46 & 0.38 & 0.25 \\
$\zeta_{2}+\widetilde{\zeta}_{2}[\%]$ & 5.52 & 4.88 & 4.4 & 3.79 & 3.37 & 0.25 \\
$\zeta_{3}+\widetilde{\zeta}_{3}[\%]$ & 4.46 & 4.34 & 4.15 & 3.79 & 3.50 & 0.25 \\
$\zeta_{4}+\widetilde{\zeta}_{4}[\%]$ & 0.45 & 0.47 & 0.49 & 0.52 & 0.56 & 0.25 \\
\hline
\end{tabular}

Figures 5(a),(b) and 6 show the peak acceleration response of this structure subjected to the ICE 2, ICE 3 and ICE 4 train models. In all cases, the maximum peak acceleration occurs at the rigidly supported beam. The ICE 2 train induces large responses of the bridge resting on soil 1 (smallest stiffness) compared to structure on the stiffer soils 5, 4, 3, and 2, as can be seen from Figure 5(a). However, in general the ICE 2 train does not cause significant acceleration responses of this structure. Another observation is that the peak acceleration of bridge 2 on soil 3 induced by the ICE 3 train is larger than for the bridge on soils 5 and 4, cf. Figure 5(b). Clearly, the ICE 4 train yields the largest bridge accelerations, as can be seen from Figure 6. For instance, the rigidly supported beam bridge model exhibits the largest acceleration $a=17.4 \mathrm{~m} / \mathrm{s}^{2}$ at $v=64.7 \mathrm{~m} / \mathrm{s}$, which is close to the resonance speed $v_{3}^{(1)}=65.5 \mathrm{~m} / \mathrm{s}$. The peak acceleration and the corresponding resonance speed for the bridge on flexible soil decrease with decreasing soil stiffness. Soil 5: $a=13.2 \mathrm{~m} / \mathrm{s}^{2}$ at $v=62 \mathrm{~m} / \mathrm{s}$ (close to $v_{3}^{(1)}=63.1 \mathrm{~m} / \mathrm{s}$ ); soil $4: a=12.2 \mathrm{~m} / \mathrm{s}^{2}$ 
at $v=61.3 \mathrm{~m} / \mathrm{s}$; soil 3: $a=10.1 \mathrm{~m} / \mathrm{s}^{2}$ at $v=59.8 \mathrm{~m} / \mathrm{s}$; soil $2: a=8.2 \mathrm{~m} / \mathrm{s}^{2}$ at $v=58.5 \mathrm{~m} / \mathrm{s}$; soil 1: $a=5.9 \mathrm{~m} / \mathrm{s}^{2}$ at $v=56.4 \mathrm{~m} / \mathrm{s}$.
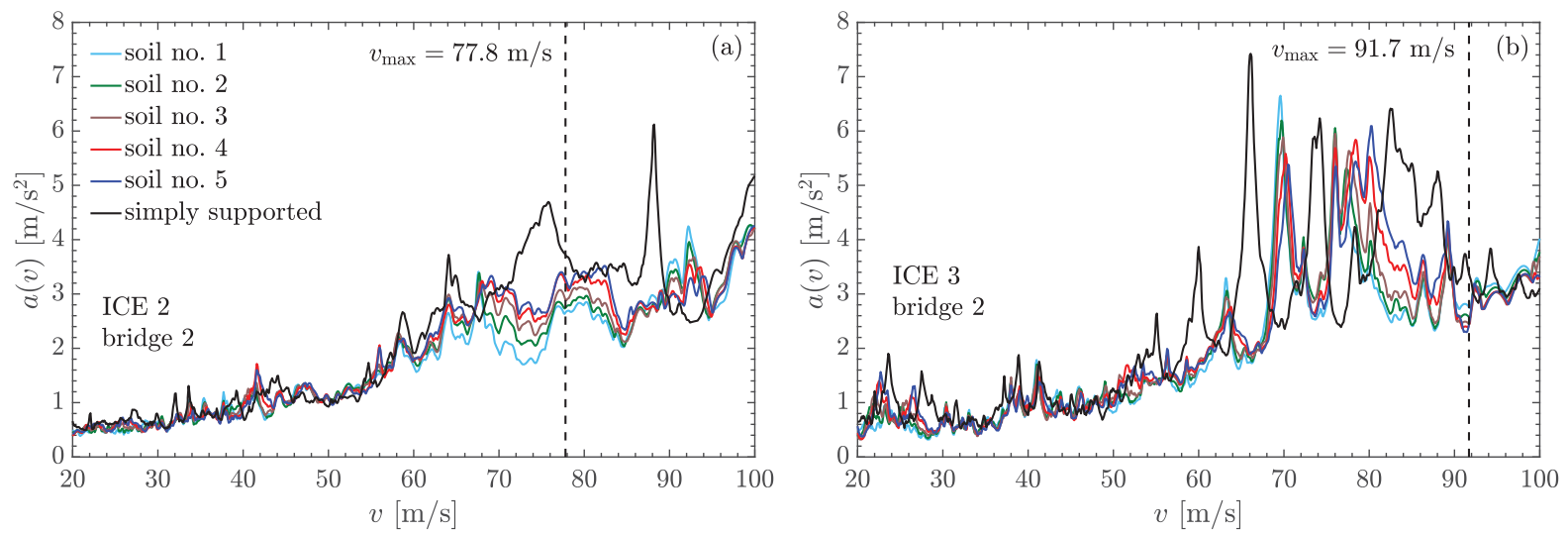

Figure 5: Maximum bridge acceleration of example bridge 2 subjected (a) to the ICE 2 train and (b) to the ICE 3 train as a function of the train speed for different soil conditions.

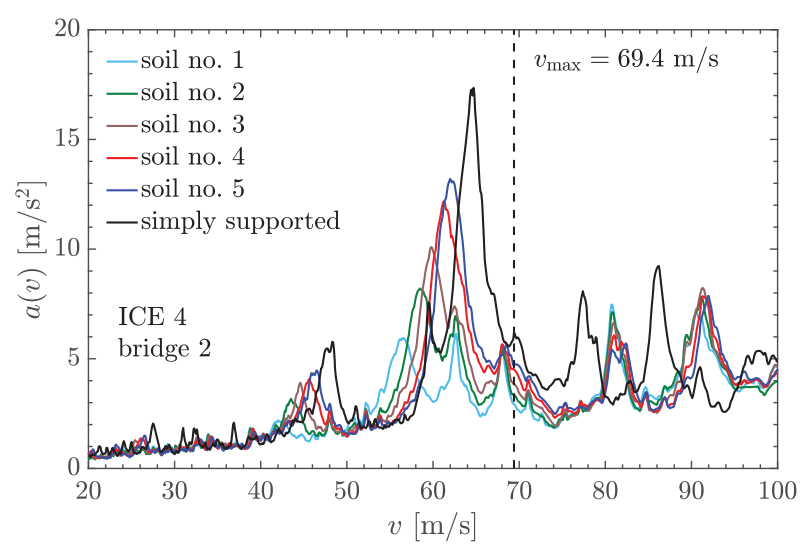

Figure 6: Maximum bridge acceleration of example bridge 2 subjected to the ICE 4 as a function of the train speed for different soil conditions.

\section{CONCLUSIONS}

In this study, a soil-bridge-train interaction model recently developed by the authors was used to efficiently evaluate the structural response of two example bridges subjected to the German high-speed trains ICE 2, ICE 3 and ICE 4. This model is based on a dynamic substructuring approach in which the bridge is modeled as a beam and the train as a mass-spring-damper system. To obtain physically meaningful results, the arrival and departure phases of the train were considered. Train-bridge interaction was explicitly considered in the approach and departure phases.

The influence of the soil-structure interaction and the bridge-train interaction on the response of the example bridges subjected to the three different train types was shown. When the soilstructure interaction is considered, the maximum acceleration at resonance is reduced due to the additional damping of the system, but simultaneously also the resonance peaks are shifted to lower train speeds. This trend is visible for the two example bridges and all three train types considered. 


\section{ACKNOWLEDGEMENTS}

The computational results presented have been achieved (in part) using the HPC infrastructure LEO of the University of Innsbruck.

\section{REFERENCES}

[1] J. Li, M. Su, The resonant vibration for a simply supported girder bridge under high-speed trains. Journal of Sound and Vibration, 224(5), 897-915, 1999.

[2] A. Doménech, M.D. Martínez-Rodrigo, A. Romero, P. Galvín, Soil-structure interaction effects on the resonant response of railway bridges under high-speed traffic. Internationl Journal of Rail Transportation, 3(4), 201-214, 2015.

[3] P. Galvín, A. Romero, J. Domínguez, Fully three-dimensional analysis of high-speed traintrack-soil-structure dynamic interaction. Journal of Sound and Vibration, 329, 5147-5163, 2010.

[4] A.M. Gharad, R.S. Sonparote, Study of direct finite element method of analysing soilstructure interaction in a simply supported railway bridge subjected to resonance. Iranian Journal of Science and Technology, Transactions of Civil Engineering, 43, 273-286, 2019.

[5] A. Romero, M. Solís, J. Domínguez, P. Galvín, Soil-structure interaction in resonant railway bridges. Soil Dynamics and Earthquake Engineering, 47, 108-116, 2013.

[6] J.Y. Shih, D.J. Thompson, A. Zervos, The effect of boundary conditions, model size and damping models in the finite element modelling of a moving load on a track/ground system. Soil Dynamics and Earthquake Engineering, 89, 12-27, 2016.

[7] A. Martínez-De la Concha, H. Cifuentes, F. Medina, A finite element methodology to study soil-structure interaction in high-speed. Journal of Computational and Nonlinear Dynamics, 13(3), 031010, 2018.

[8] P. Galvín, S. François, M. Schevenels, E. Bongini, G. Degrande, G. Lombaert, A 2.5D coupled FE-BE model for the prediction of railway induced vibrations. Soil Dynamics and Earthquake Engineering, 30, 1500-1512, 2010.

[9] B. Hirzinger, C. Adam, P. Salcher, Dynamic response of a non-classically damped beam with general boundary conditions subjected to a moving mass-spring-damper system. International Journal of Mechanical Sciences, 185, 105877, 2020.

[10] K. Knothe, S. Stichel, Railway Vehicle Dynamics. Springer International, 2017.

[11] K. Popp, W. Schiehlen, Ground Vehicle Dynamics. Springer International, 2010.

[12] A. Brandt, Noise and Vibration Analysis. John Wiley and Sons, Ltd., 2010.

[13] B. Hirzinger, Contributions to modeling and assessment strategies in railway bridge dynamics. Dissertation, University of Innsbruck, 2020. 
[14] C. Adam, B. Hirzinger, Simplified dynamic response analysis of a railway bridge considering soil-structure interaction. In: Proc. XI European Conference on Structural Dynamics (EURODYN 2020), virtual conference (Papadrakakis, M., Fragiadakis, M., Papadimitriou, C., eds.), November 23-26 2020, 9 pp, 2020.

[15] UIC Leaflet 650, Standard designation of axle arrangement on locomotives and multipleunit sets. 5th edition of 1.1.83.

[16] A. Doménech, Influenca del modelo de vehículo en la predicción del comportamiento a flexión de puentes isostáticos de ferrocarril para tráfico de alta velocidad (in Spanish). Dissertation, Universitat Politecnica de Valencia, 2014.

[17] M. Hädrich, Untersuchungen zur dynamischen Bauwerk-Fahrzeug-Wechselwirkung bei Eisenbahnbrücken kurzer Spannweite (in German). Masterthesis, Bauhaus-Universität Weimar, 2008.

[18] A. Firus, H. Berthold, J. Schneider, G. Grunert, Untersuchungen zum dynamischen Verhalten einer Eisenbahnbrcke bei Anregung durch den neuen ICE 4 6. VDI-Fachtagung Baudynamik, 233-248, 2018.

[19] L. Frýba, Dynamic of Railway Bridges. Thomas Telford, 1996.

[20] C. Adam, B. Hirzinger, Ein Modell mit Boden-Bauwerk-Interaktion zur dynamischen Berechnung von Eisenbahnbrücken (in German) [A model with soil-structure interaction for the dynamic analysis of railway bridges]. Bauingenieur, 95, 289-298, 2020.

[21] Y.B. Yang, J.D. Yau, Y.S. Wu, Vehicle-Bridge Interaction Dynamics. World Scientific Publishing Company Incorporated, 2004. 